\title{
Components of hospital-to-home care interventions for patients with heart failure in Japan: An integrative review
}

\author{
Mai Yoshimura, MS, RN, $\mathrm{PHN}^{1}$ (D), and Naomi Sumi, PhD, RN, $\mathrm{PHN}^{2}$ (iD \\ ${ }^{1}$ Graduate School of Health Sciences, Hokkaido University, Hokkaido, Japan, and ${ }^{2}$ Department of Fundamental \\ Nursing, Faculty of Health Sciences, Hokkaido University, Hokkaido, Japan
}

\begin{abstract}
Hospital-to-home care is important for improving the quality of life (QOL) of patients with heart failure (HF). However, there is little evidence of outcomes regarding hospital-to-home care interventions in Japan. Thus, this integrative review aimed to identify the components and outcomes of hospital-to-home care interventions for patients with HF in Japan. Electronic databases, such as MEDLINE, CINAHL, and Ichushi-Web, were systematically searched, and all forms of hospital-to-home care interventions in Japan were examined. Studies regarding transitional care, discharge planning, home care, and disease management were included. The characteristics and results of the intervention studies were summarized. Furthermore, we analyzed the components of hospital-to-home care interventions and considered the effective interventions for patients with HF, based on statistically significant results. Ten articles including nine interventions were reviewed. The average age of intervention participants ranged from 64 to 77.5 years old, and the sample sizes in the intervention groups ranged from 11 to 192 participants. The intervention components were categorized as follows: "hospital-based components," "home- and outpatient-based components," and "both hospital- and home-based components." The main intervention components comprised structured education, lifetime counseling, and follow-ups via telephone and video calls. The clinical outcomes included readmission, mortality, and QOL, measured up to 24 months after the interventions. There was limited evidence of interventions being continued from the hospital to home, follow-up immediately after discharge, and nurse home visits in Japan. Further studies are necessary to evaluate the outcomes of patients' experiences immediately after discharge and the quality of care transition.
\end{abstract}

\section{Keywords}

heart failure, patient discharge, quality of health care, transitional care

JINR 2022, 1(1), e2021-0001

\section{Introduction}

Heart failure (HF) is a life-threatening cardiac condition that is becoming increasingly prevalent. It is caused by defects in the cardiac structure, function, or both, which can ultimately lead to impaired peripheral circulation and organ oxygenation (Rosa et al., 2019). The number of individuals with HF in Japan is estimated to increase to 1.3 million by 2030
(Okura et al., 2008) and at least 26 million people worldwide (Savarese \& Lund, 2017). The incidence of HF-related hospitalization is the highest in the first 30 days after patients' discharge, and the majority of HF-related rehospitalization cases in Japan occur within 90 days of discharge (Ishihara et al., 2020); the rate of readmission for HF is 40\% within 1 year after discharge (Tsutsui et al., 2006). Rehospitalization burdens patients and affects their quality of

Correspondence: N. Sumi. Email: nsumi@ hs.hokudai.ac.jp

Received: May 27, 2021, Accepted: November 18, 2021, Published: February 24, 2022

Copyright (C) 2022 The Japan Society of Nursing Research

This work is licensed under the Creative Commons Attribution International License (CC BY-NC-SA). 
life (QOL). Hence, proper care transitions for patients, who are discharged from the hospital, are crucial to improve their QOL and reduce preventable hospital readmissions.

Despite substantial advancements in treatments and multidisciplinary care, HF management remains a global health challenge for healthcare providers. In HF management, hospital-to-home transitional care has become an important intervention to improve the clinical outcomes of chronic older patients as well as the rates of rehospitalization for HF (Murtaugh et al., 2017). Transitional care is defined as a set of actions designed to ensure the coordination and continuity of healthcare while patients are transferred between different locations or different levels of care within the same location (Coleman \& Boult, 2003). Older patients, who are discharged to their homes, undergo a period of vulnerability in which they must learn to adjust and adapt to their new self-care regimen (Werner et al., 2019). In a study regarding the discharge experiences of patients with HF, it was found that these patients were struggling with daily self-care, symptom monitoring, severity judgment, medication management, inadequate discharge preparation, and poor care coordination (Nordfonn et al., 2019). Therefore, hospital-tohome transitional care is vital to the improvement in QOL of patients with $\mathrm{HF}$ and to ensure a smooth transfer from the hospital to their homes.

There have been several systematic reviews on transitional care interventions for patients with HF (Feltner et al., 2014; Fergenbaum et al., 2015; Mai Ba et al., 2020; Van Spall et al., 2017). However, none have included Japanese intervention studies. The Japanese healthcare system is extremely different from those in the United States, the United Kingdom, Sweden, Germany, Australia, and China, where many transitional care intervention studies have been conducted, and it is likely that patients and their families face different challenges. In Japan, older adults (primary insured adults aged $\geq 65$ years and secondary insured persons aged 40-64 years) can use public long-term care insurance services, such as home-visit nursing. When the Japanese government promotes home care for older adults, it differentiates hospital care and home care in the acute, convalescent, and chronic phases. Therefore, to enhance transitional care, discharge support departments have been established in acute care hospitals. Nurses who specialize in discharge planning play an important role in smooth and timely care transitions for patients with high care needs (Tomura et al., 2011). Moreover, ward nurses play a key role in coordinating multidisciplinary tasks in transitional care in Japan. In contrast, transitional care in the United States and the United Kingdom is coordinated by transitional care nurses, who are known as nurse practitioners and advanced practice nurses. Transitional care nurses provide comprehensive discharge planning and home follow-ups through care transitions from hospital to home. Therefore, it is necessary to identify the characteristics of the components of hospital-to-home care interventions in Japan. Moreover, medical staff needs to identify the outcomes of these transitions to determine which clinical interventions can be implemented in practice (Son \& You, 2015). Thus, this review aimed to analyze the characteristics of the components and outcomes of hospitalto-home care interventions for patients with HF in Japan and to consider recommended interventions in the Japanese healthcare system through comparison to transitional care in other countries.

\section{Methods}

\section{Study Design}

An integrative review approach was adopted to capture the effective components of hospital-to-home care interventions for patients with HF in Japan. The methodology described by Whittemore and Knafl (2005) was adopted, which involves identifying the problem, searching the literature, evaluating the data, and presenting the findings. Integrative reviews summarize previous literature to provide a more comprehensive understanding of a particular topic and allow for the inclusion of the broadest type of research. Various perspectives on components related to the effectiveness of existing transitional care interventions for patients with $\mathrm{HF}$ in Japan were collected, and the resulting synthesized information provides insights for nursing practice.

\section{Problem Identification}

The three research questions that we aimed to answer in this integrative review were as follows: "What are the characteristics of the components of hospital-to-home care interventions for patients with HF in Japan?," "What are the outcome measures and endpoints of hospital-to-home interventions for patients with HF in Japan?", and "What are the recommended hospital-to-home interventions for patients with HF in the Japanese healthcare system?" The evaluated characteristics included the nature of the interventions, composition of the target population, and outcome measures and endpoints.

\section{Literature Search}

Relevant English and Japanese articles were searched from the electronic databases MEDLINE, CINAHL, and IchushiWeb. The following key words were used: "heart failure" AND "(home care OR discharge planning OR transitional care OR disease management)" AND "Japan." Articles published until June 2020 were searched. Studies regarding (1) transitional care and discharge planning interventions in hospitals and (2) home care and disease management for patients discharged from acute care hospitals were included. Meanwhile, studies that involved no interventions, interventions that did not include hospital-to-home care, interven- 


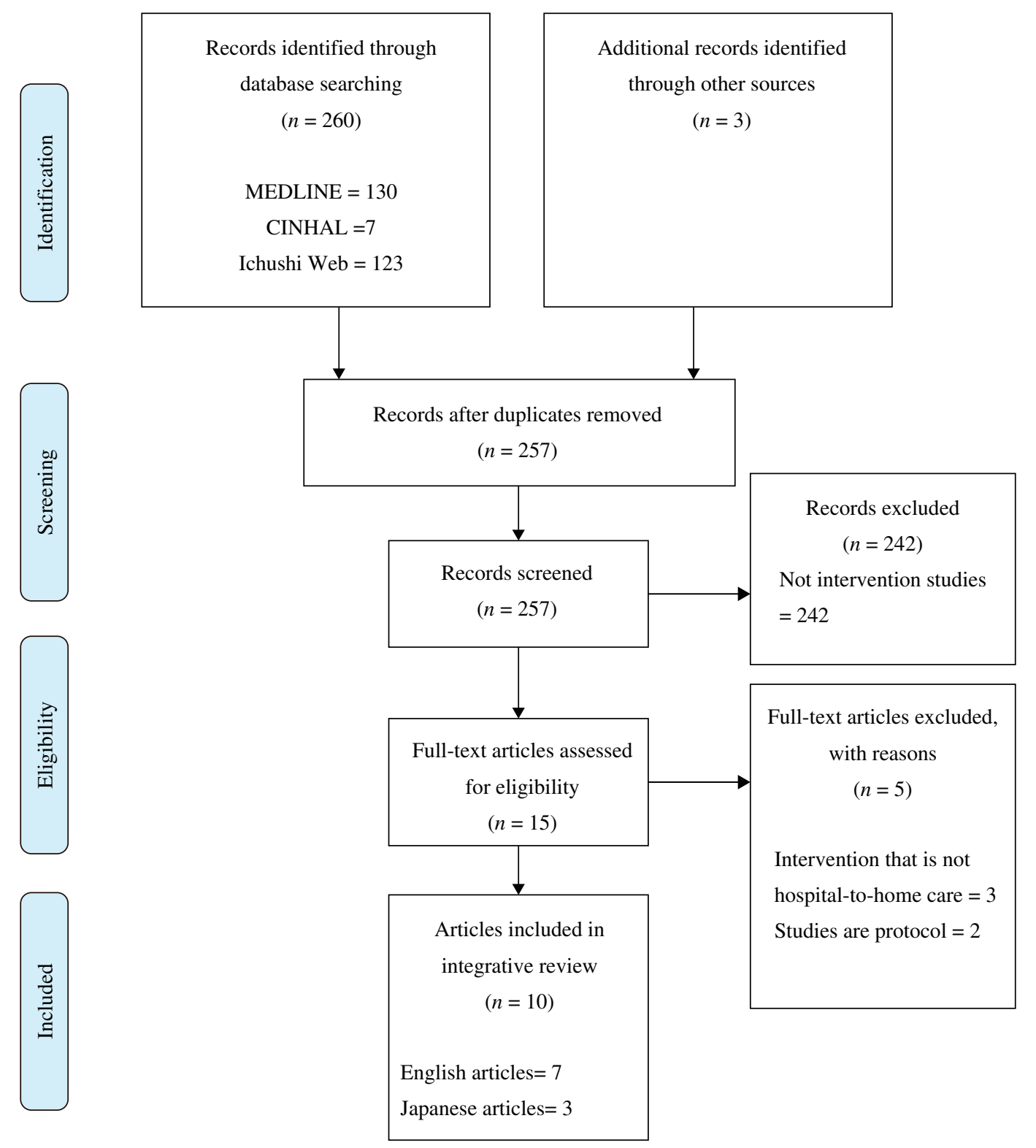

Figure 1. Flowchart of the study retrieval and selection process.

tions without nursing support, and study protocols were excluded. After duplicates were removed, 257 articles were initially identified in the three databases. A total of 242 articles were excluded because they were not intervention studies. The remaining 15 articles were retrieved mainly due to their contents of the intervention and results. Five articles were excluded because three articles did not include hospital-to-home care interventions and nursing support, and two articles were study protocols. Finally, 10 papers, 7 in English and 3 in Japanese, were reviewed. A flowchart of the article selection process is shown in Figure 1. Two authors independently screened and discussed the results of the literature search.

\section{Data Evaluation}

All included studies were critically assessed according to the Mixed Methods Appraisal Tool (MMAT, version 2018), which was developed to critically appraise different study designs (Hong et al., 2019). The MMAT allows for a critical appraisal process in reviews of systematic mixed studies, by providing methodological quality criteria for different study designs, within a single tool. First, two optional screening questions were evaluated. Secondly, the appropriate categories of study designs were applied to the five categories, with different methodological quality criteria used depending on the study design and methods: qualitative, quantitative randomized controlled trials (RCTs), quantitative non- 
randomized, quantitative descriptive, and mixed methods (Hong et al., 2018). Excluding studies with low methodological quality is usually discouraged (Hong et al., 2018).

In our study, two screening questions obtained from the MMAT manual were applied to all the 10 reviewed articles, i.e., "Are there clear research questions?" and "Do the collected data address the research questions?" All 10 studies satisfied the two screening questions. The appropriate categories of studies to be appraised were then evaluated. The MMAT scores are presented in Table 1. Of the six RCT studies, two were unclear as to whether randomization was appropriately performed, and three were unclear as to whether outcome assessors were blinded to the intervention provided. Other quality appraisal criteria were satisfied in RCT studies. One non-RCT study showed that potential confounders could not be accounted for in the design and analysis. All three quantitative descriptive studies satisfied all quality appraisal criteria.

\section{Data Analysis}

The characteristics and results of the intervention studies are summarized in Table 1. It summarizes the following: (a) study information (i.e., authors' names, year of publication, sample size, and average age of patients); (b) information regarding hospital-to-home care interventions (i.e., intervention contents, intervention provider, and intervention duration); and (c) major findings regarding the outcomes. The intervention components were analyzed according to the categories included in the studies. These included predischarge and postdischarge interventions. The outcome measures/endpoints, evaluation times, and frequency of use are summarized. Finally, the components of the recommended practices were considered from interventions that were statistically effective.

\section{Results}

Characteristics of the Included Studies and Their Participants

This review included 10 articles regarding 9 hospital-tohome care interventions for patients with HF. We have summarized all the studies in Table 1. In total, 3 of the 10 studies were conducted in Japanese (Ishibashi et al., 2018; Ito \& Tanaka, 2018; Yamazaki et al., 2016). Regarding the research designs employed, there were six RCT studies (Kato et al., 2016; Kotooka et al., 2018; Mizukawa et al., 2019; Otsu \& Moriyama, 2011, 2012; Tsuchihashi-Makaya et al., 2013), three retrospective studies (Ito \& Tanaka, 2018; Kinugasa et al., 2014; Yamazaki et al., 2016), and one preand post-test study (Ishibashi et al., 2018). The participants in these studies were patients with HF, not including their families. The sample sizes in the intervention groups ranged from 11 to 192, and the age of the participants averaged be- tween 64 and 77.5 years old. All RCT studies excluded patients with cognitive impairment, severe comorbidities, and end-of-life diseases. In seven of the nine interventions, nurses served as the primary providers. In four studies, multidisciplinary teams provided the interventions. Members of multidisciplinary teams consisted of nurses, cardiologists, physiotherapists, pharmacists, dietitians, and social workers. Interventions lasted from approximately 1 hour to 15 months. Four of the interventions took place at hospitals, another four occurred at patients' homes or as outpatients, and one transpired at both a hospital and the patient's home.

\section{Components of Hospital-to-home Care Interventions}

We categorized nine components of hospital-to-home care transitions for patients with HF, as shown in Table 2. These were categorized into "hospital-based components," "homeand outpatient-based components," and "both hospital- and home-based components," respectively. Hospital-based components included discharge planning, including discharge screening, discharge conferences, and care coordination. Home- and outpatient-based components included lifetime counseling by nurses, follow-up telephone and video calls, self-monitoring support, telemonitoring, and nurse home visits. As for both hospital- and home-based components, these included nurse-led education, disease management, and multidisciplinary care. The component with the highest frequency was nurse-led education. All education interventions were predominantly delivered by nurses. Participants and intervention providers used printed materials, booklets, checklists, and calendars for lifestyle modification and selfmonitoring. Face-to-face individual structured programs were delivered. There were no educational interventions for the patient population. The second most frequent form of intervention was lifetime counseling by nurses, particularly regarding lifestyle, self-care, and problems. Counseling was provided via individual educational programs, phone calls, home visits, and video calls.

Outcome Measures and Endpoints of Hospital-to-home Care Interventions

We summarized the outcomes and endpoints of hospital-tohome care transitions for HF in Table 3. Outcomes included all-cause death and rehospitalization due to worsening HF, HF status, health-related QOL, HF-specific QOL, anxiety and depression, self-care, self-efficacy, compliance, and HF knowledge. The highest frequency of measured outcomes was readmission or hospital admission, and all studies included readmission or hospital admission as outcomes. The second highest frequency of outcomes was death, or mortality, which was noted in six studies. The highest frequency of patient-reported outcomes was QOL in five studies. Outcomes were assessed at 1-24 months after the intervention. 


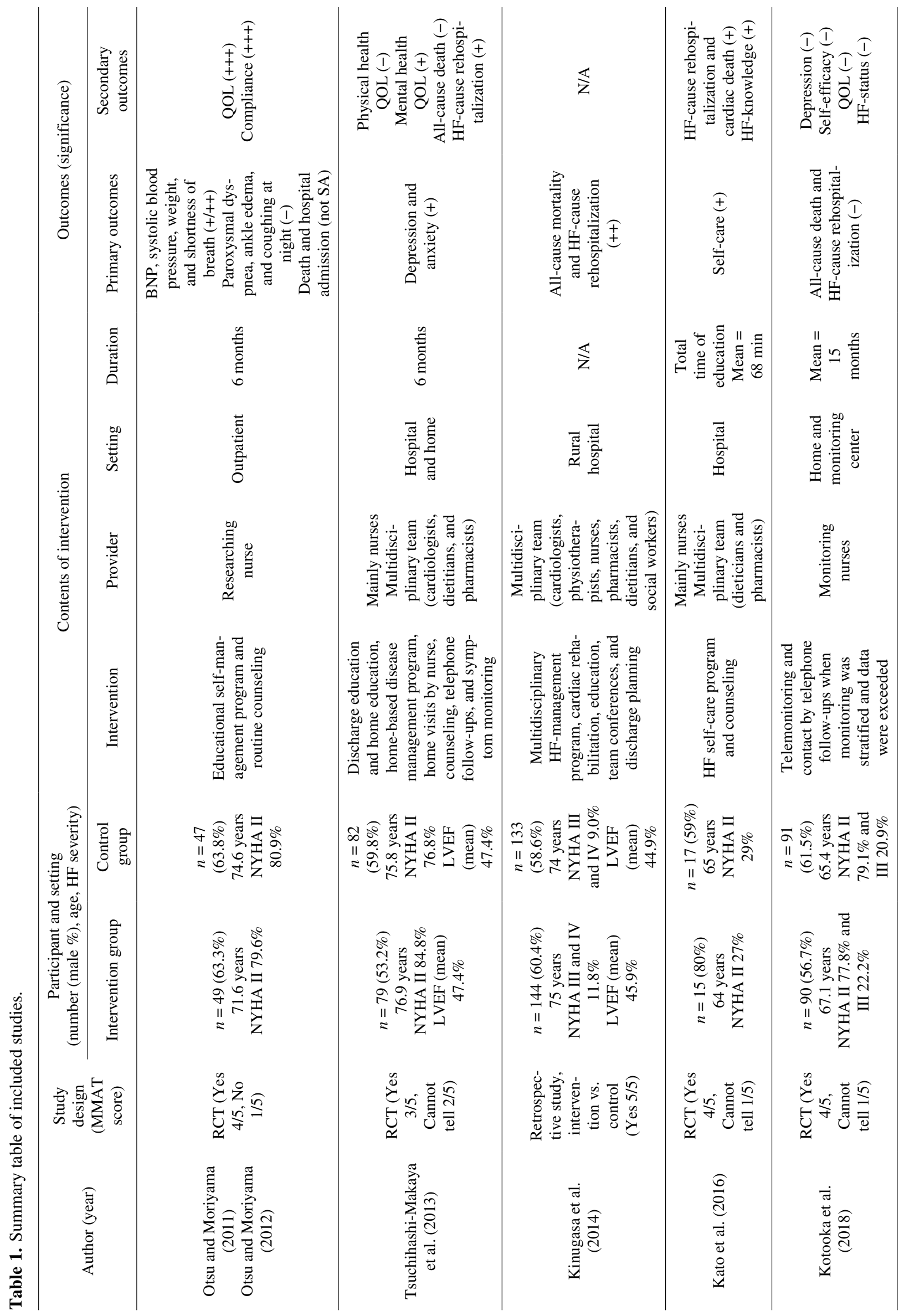




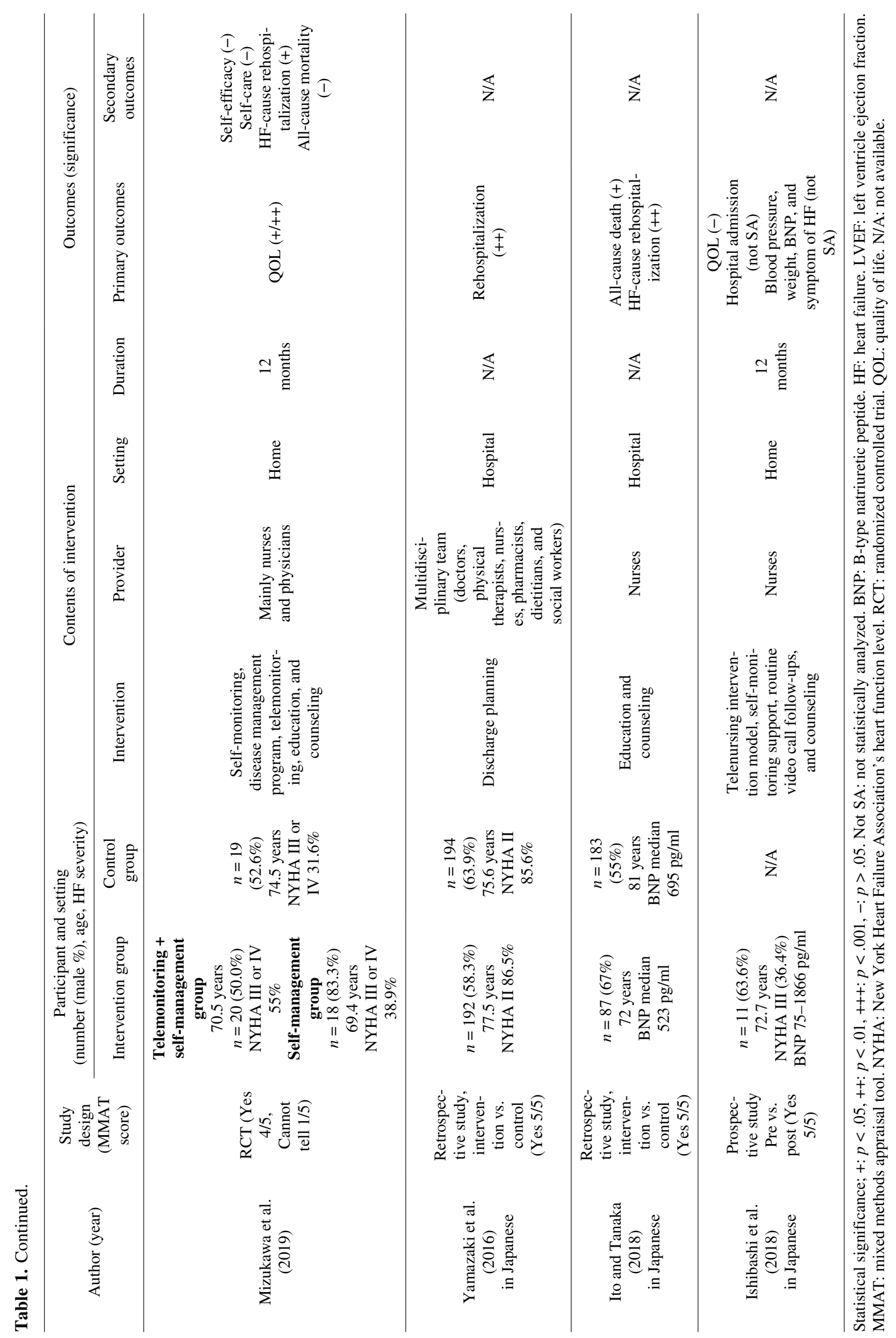


Table 2. Components of hospital-to-home care interventions.

\begin{tabular}{|c|c|c|c|}
\hline \multicolumn{2}{|r|}{ Components } & \multirow{2}{*}{ Contents } & \multirow{2}{*}{$\begin{array}{c}\text { No. of } \\
\text { interventions }\end{array}$} \\
\hline Hospital-Based & Home- and Outpatient-Based & & \\
\hline $\begin{array}{l}\text { Discharge } \\
\text { planning }\end{array}$ & N/A & $\begin{array}{l}\text {-Screening of discharge planning, discharge support conferences, and care } \\
\text { coordination with multiple multidisciplinary care provided inside and out- } \\
\text { side the hospital }\end{array}$ & 2 \\
\hline \multirow{12}{*}{ N/A } & $\begin{array}{l}\text { Lifetime counseling by } \\
\text { nurses }\end{array}$ & $\begin{array}{l}\text { - Counseling support regarding lifestyle, self-care, and problems encountered } \\
\text { during home visits, interviews during outpatient visits, telephone calls, and } \\
\text { video calls }\end{array}$ & 5 \\
\hline & \multirow{3}{*}{$\begin{array}{l}\text { Follow-ups via telephone and } \\
\text { video call by nurses }\end{array}$} & $\begin{array}{l}\text {-Two types of follow-ups: regular follow-ups and follow-ups only in the } \\
\text { event of an abnormality }\end{array}$ & \multirow{3}{*}{3} \\
\hline & & $\begin{array}{l}\text {-Regular follow-up assessments and care regarding HF symptoms, general } \\
\text { health status, lifestyle, and self-care at home by nurses }\end{array}$ & \\
\hline & & $\begin{array}{l}\text {-When necessary, nurses consult a multidisciplinary team and coordinate } \\
\text { social support and hospital visits. }\end{array}$ & \\
\hline & \multirow{2}{*}{ Self-monitoring support } & $\begin{array}{l}\text {-Self-monitoring support through face-to-face interventions at outpatient } \\
\text { visits }\end{array}$ & \multirow{2}{*}{2} \\
\hline & & $\begin{array}{l}\text {-The implementation of self-monitoring regarding patients' HF status and } \\
\text { the interpretation of measured values using video calls are supported. }\end{array}$ & \\
\hline & \multirow{4}{*}{ Telemonitoring } & $\begin{array}{l}\text {-Participants measure their body weight, blood pressure, pulse, and body } \\
\text { composition at home using a monitoring device. }\end{array}$ & \multirow{4}{*}{2} \\
\hline & & -The nurses at the monitoring centers check the measured data every day. & \\
\hline & & $\begin{array}{l}\text {-In case of abnormal data, the patient is called, and the causes of the abnor- } \\
\text { malities are assessed; then, either the patient is provided with advice, a visit } \\
\text { by the physician is arranged, or home care is coordinated. }\end{array}$ & \\
\hline & & -Families can also access the remote monitoring system. & \\
\hline & \multirow[t]{2}{*}{ Nurse home visits } & $\begin{array}{l}\text {-Home-visit nursing care once every } 2 \text { weeks until } 2 \text { months after discharge } \\
\text { for symptom monitoring, general health status assessments, education, and } \\
\text { consultations }\end{array}$ & \multirow[t]{2}{*}{1} \\
\hline & & -First visit is conducted within 2 weeks after discharge. & \\
\hline \multirow{8}{*}{\multicolumn{2}{|c|}{ Nurse-led education }} & $\begin{array}{l}\text {-Self-care and self-management education through a face-to-face individual } \\
\text { program }\end{array}$ & \multirow{8}{*}{7} \\
\hline & & $\begin{array}{l}\text {-Structured educational program and discharge education based on models } \\
\text { (e.g., behavior change model, cognitive behavior, and health belief model) }\end{array}$ & \\
\hline & & $\begin{array}{l}\text {-Educational program using tools such as booklets and checklists by nurses, } \\
\text { pharmacists, and nutritionists }\end{array}$ & \\
\hline & & $\begin{array}{l}\text {-The participants record information regarding their lifestyles, and the inter- } \\
\text { vention nurses provide individual feedback. }\end{array}$ & \\
\hline & & $\begin{array}{l}\text {-Advice and consultation support regarding self-management methods at } \\
\text { home are provided. }\end{array}$ & \\
\hline & & $\begin{array}{l}\text {-Long- and short-term goals with the participants are developed and evaluat- } \\
\text { ed. }\end{array}$ & \\
\hline & & $\begin{array}{l}\text {-Education is provided regarding items that a target participant is interested } \\
\text { in. }\end{array}$ & \\
\hline & & $\begin{array}{l}\text {-Educational contents include "heart failure," "examination and treatment," } \\
\text { "self-monitoring," "lifestyle," and "symptoms and urgency when consulta- } \\
\text { tion is required," as well as internal medication management, weight man- } \\
\text { agement, salt restriction, etc. }\end{array}$ & \\
\hline & ase management & $\begin{array}{l}\text {-Includes symptom monitoring, education, consultations, and the adjustment } \\
\text { of social support via home visits and telephone follow-ups by nurses in addi- } \\
\text { tion to follow-ups by cardiologists }\end{array}$ & 2 \\
\hline \multicolumn{2}{|c|}{ Multidisciplinary care } & $\begin{array}{l}\text {-Patient education and conferences are conducted by a multidisciplinary } \\
\text { team. } \\
\text { - Cardiac rehabilitation } \\
\text { - Progress sharing regarding the intervention with the team }\end{array}$ & 4 \\
\hline
\end{tabular}

HF: heart failure. N/A: not available.

No. of interventions: Number of interventions in which the applicable component was performed out of all nine interventions. 
Table 3. Summary table of outcome measures/endpoints.

\begin{tabular}{|c|c|c|c|}
\hline Outcome measures/Endpoints & Scale/Measure contents & $\begin{array}{l}\text { Time of data collection } \\
\text { (follow-up period) }\end{array}$ & $\begin{array}{l}\text { No. of } \\
\text { interventions }\end{array}$ \\
\hline Rehospitalization & $\begin{array}{l}\text { All-cause rehospitalization, rehospitalization due to worsening } \\
\mathrm{HF} \text {, hospital admission (patients with a history of hospitaliza- } \\
\text { tions), number of readmissions, period until readmission after } \\
\text { discharge, and hospitalization period at the time of readmis- } \\
\text { sion }\end{array}$ & $\begin{array}{l}\text { At } 3,6,9,12 \text {, and } 24 \text { months } \\
\text { after discharge (31 months) }\end{array}$ & 9 \\
\hline Death & All-cause death, cardiac death, and period until death & $\begin{array}{l}\text { At } 3,6,9,12 \text {, and } 24 \text { months } \\
\text { after discharge ( } 31 \text { months) }\end{array}$ & 6 \\
\hline QOL & $\begin{array}{l}\text { (HF-specific scales) } \\
\text { MacNew Heart Disease Health-Related Quality of Life } \\
\text { Questionnaire and Minnesota Living with Heart Failure Ques- } \\
\text { tionnaire } \\
\text { (generic scales) } \\
\text { SF-8 Health Survey and the MOS 36-Item Short-Form Health } \\
\text { Survey }\end{array}$ & $\begin{array}{c}\text { At } 3,6,9,12 \text {, and } 24 \text { months } \\
\text { after discharge }\end{array}$ & 5 \\
\hline Anxiety and depression & $\begin{array}{l}\text { Hospital Anxiety and Depression Scale, } \\
\text { Patient Health Questionnaire- } 9\end{array}$ & $\begin{array}{l}\text { At 2, 6, and } 12 \text { months after } \\
\text { discharge }\end{array}$ & 2 \\
\hline Self-care & European Heart Failure Self-Care Behaviour Scale & $\begin{array}{l}\text { At } 6,12,18 \text {, and } 24 \text { months } \\
\text { after discharge }\end{array}$ & 2 \\
\hline HF status & $\begin{array}{l}\text { BNP, NYHA, blood pressure, weight, and deterioration in the } \\
\text { symptoms related to HF }\end{array}$ & $\begin{array}{l}\text { At } 3,6,9,12 \text {, and } 24 \text { months } \\
\text { after discharge }\end{array}$ & 2 \\
\hline Self-efficacy & $\begin{array}{l}\text { Chronic Disease Self-Efficacy Scale and General Self-Effica- } \\
\text { cy Scale }\end{array}$ & $\begin{array}{l}\text { At } 6,12,18 \text {, and } 24 \text { months } \\
\text { after discharge }\end{array}$ & 2 \\
\hline Compliance & $\begin{array}{l}\text { Four-point scale: sodium-restricted diet, medicine administra- } \\
\text { tion, activities or exercise, smoking and drinking cessation, } \\
\text { self-monitoring of weight, and symptoms of HF }\end{array}$ & $\begin{array}{c}\text { At } 3,6,9,12 \text {, and } 24 \text { months } \\
\text { after discharge }\end{array}$ & 1 \\
\hline Knowledge about HF & 15-item Japanese HF-knowledge scale & $\begin{array}{l}\text { At } 1 \text { and } 6 \text { months after } \\
\text { discharge }\end{array}$ & 1 \\
\hline
\end{tabular}

BNP: B-type natriuretic peptide. HF: heart failure. QOL: Quality of life. NYHA: New York Heart Association's heart function level.

No. of interventions: Number of interventions that measured the applicable outcome/endpoints out of all nine interventions.

\section{Effects of Hospital-to-home Care Interventions}

The results of the outcome studies are shown in Table 1. Six out of the nine interventions led to a statistically significant reduction in the rate of readmission, compared to the control groups (Ito \& Tanaka, 2018; Kato et al., 2016; Kinugasa et al., 2014; Mizukawa et al., 2019; Tsuchihashi-Makaya et al., 2013; Yamazaki et al., 2016). The studies that showed statistically significant readmissions included components of nurse-led education, lifetime counseling by nurses, regular follow-ups via telephone, nurse home visits, self-monitoring support, disease management, and multidisciplinary care. Three out of the six interventions led to a statistically significant reduction in the rate of death (Ito \& Tanaka, 2018; Kato et al., 2016; Kinugasa et al., 2014). Of the five interventions (Ishibashi et al., 2018; Kotooka et al., 2018; Mizukawa et al., 2019; Otsu \& Moriyama, 2011; TsuchihashiMakaya et al., 2013), three led to a significantly improved QOL in the intervention group, compared to the control group (Mizukawa et al., 2019; Otsu \& Moriyama, 2011; Tsuchihashi-Makaya et al., 2013). The studies that showed

8 of 12 statistically significant improvement in QOL included the components of education, counseling, follow-ups via telephone, nurse home visits, self-monitoring support, and disease management. One of two studies indicated a statistically significant improvement in anxiety and depression (Tsuchihashi-Makaya et al., 2013). Statistically, self-efficacy did not improve significantly. Telemonitoring and the assessment of acquired data, such as weight and blood pressure, and follow-up only at the time of abnormality, did not significantly change the clinical outcomes (Kotooka et al., 2018).

\section{Discussion}

In this integrative review, we revealed the components and outcomes of hospital-to-home care interventions for patients with HF in Japan. We analyzed components that were categorized into "hospital-based components," "home- and outpatient-based components," and "both hospital- and home-based components." We identified only one study in Japan that included both hospital- and home-based interven- 
tions (Tsuchihashi-Makaya et al., 2013), in contrast to the numerous intervention studies overseas. In Japan, there is still a lack of evidence regarding the effectiveness of intervention methods for the transitional care of patients with HF; thus, further studies evaluating both pre- and postdischarge interventions are needed. The studies we investigated show that nurse-led patient education, counseling, and discharge planning are important components in interventions. These findings are similar to those of previous studies (Bryant-Lukosius et al., 2015; Rice et al., 2018). Studies on transitional care for patients with HF have been predominantly conducted in the United States, the United Kingdom, Spain, Sweden, Canada, and Australia. Early follow-ups and contact, such as medication and symptom management within 3 days after discharge, were the main forms of intervention in transitional care for patients with HF (Coleman et al., 2006; Mai Ba et al., 2020). However, a few early postdischarge interventions in the investigated studies involved home visits within 14 days after discharge and follow-up assessments 2 months after discharge (Tsuchihashi-Makaya et al., 2013). Therefore, early postdischarge interventions and medication management at home may require further verification of their effectiveness. The evidence regarding homevisit nursing outcomes further promotes the need and effectiveness of home-visit nursing, immediately after discharge in Japan.

The participants of all the investigated intervention studies were patients, and the interventions did not involve the families of the patients. Older patients with HF often require long-term care, livelihood support, and social support. The transitional care model and the care transition interventions lead to the establishment of a trustworthy relationship with family caregivers and consider family needs involved in patient care (Coleman et al., 2015; Naylor et al., 2018). A patient's family also influences HF self-care and outcomes (Dunbar et al., 2008); hence, research on support and interventions that includes family members may be necessary, with investigation on caregiver education and engagement needed.

We uncovered the outcome measures, endpoints, and measurement times involved in the interventions. The most frequent outcome was rehospitalization. The most common patient-reported outcome was QOL, similar to that reported in a previous study (Mai Ba et al., 2020). Both the HFspecific QOL scale and generic QOL scale were significantly improved (Mizukawa et al., 2019; Otsu \& Moriyama, 2012; Tsuchihashi-Makaya et al., 2013), and the recommended HF-specific scale, namely, the Minnesota Living with Heart Failure Questionnaire, was used (Kelkar et al., 2016; Kotooka et al., 2018; Mizukawa et al., 2019). However, emergency department visits and costs were not measured in the Japanese intervention studies investigated. For this reason, it can be said that there are few emergency vis- its in Japan due to outpatient visits being planned 2-4 weeks after discharge as well as the difficulty in collecting cost data. Little is known about the hospitalization costs associated with HF in Japan (Kanaoka et al., 2019; Kotooka et al., 2018). Cost evaluations may need to be assessed in the future to strengthen the evidence regarding the effectiveness of hospital-to-home care in patients with HF. Canadian and Chinese RCT studies on heart disease included patientreported outcomes and patient-experience measures of discharge preparedness and care transition quality measure (Cao et al., 2017; Van Spall et al., 2018; Van Spall et al., 2019). The patient and caregiver's desired outcomes of care transitions can be identified from participant experience (Mitchell et al., 2018). The use of patient-experience measures that capture the quality of care transitions or patient concerns and anxiety should be implemented in Japan, and for this purpose, the use of a validated quality of care transition scale, such as the Care Transitions Measure (Coleman et al., 2005; Yoshimura et al., 2018), PREPARED (Graumlich et al., 2008), or the Readiness for Hospital Discharge Scale (Weiss \& Piacentine, 2006), should be adopted. It is necessary to develop a validated tool for capturing patient experiences, such as those related to their concerns, lifestyle, and self-care, when counseling and assessing outcomes. Older patients immediately after discharge are also vulnerable to a higher risk of adverse health outcomes and experience feelings of uncertainty (Blakey et al., 2017; van Seben et al., 2019). Although the measurement times for the interventions were between 1 and 24 months after discharge or intervention in this review, it may be necessary to evaluate immediately after or 1 week after discharge.

Finally, recommended intervention components for patients with HF were considered, including regular and structured counseling and education, follow-ups via telephone by nurses, nurse home visits, multidisciplinary care, and disease management. Studies that combine multiple intervention components are shown to be effective. In previous metaanalyses on transitional care for patients with $\mathrm{HF}$, nurse home visits were the most recommended care practice that care providers can apply (Feltner et al., 2014; Van Spall et al., 2017). However, only one intervention included nurse home visits in this review. In addition, most of the elderly patients are registered for long-term care insurance, but only a small proportion of these patients receive home-visit services in Japan (Takabayashi et al., 2016). Home-visit nursing care should be actively provided as well as visits immediately after discharge for older patients with HF. Research on the effectiveness of home-visit nursing for patients with HF in Japan is urgently needed.

A limitation of our study is that we did not search all gray literature, such as dissertations and non-peer-reviewed articles, and the limited number of intervention studies regarding HF in connection to hospital-to-home care transi- 
tions is also a limitation.

\section{Conclusions}

This integrative review uncovered the components of hospital-to-home care interventions for patients with $\mathrm{HF}$, their related outcome measures, and their measurement times. Hospital-to-home care interventions should include both hospital- and home-based care and combine multiple intervention components by nurses and multidisciplinary teams. With respect to outcome evaluation, it is necessary to assess outcomes immediately after discharge, as well as the quality of care transitions. The findings from this literature review highlight the need for further research on the effectiveness of nurse home visits and interventions that involve the families of patients with $\mathrm{HF}$.

\section{Author Contributions}

M. Y. and N. S. contributed to the conception and design of this study, carried out the analysis, drafted the manuscript, and approved the final manuscript.

\section{Declaration of Conflicting Interests}

The authors declare no conflict of interests.

\section{References}

Blakey, E. P., Jackson, D., Walthall, H., \& Aveyard, H. (2017). What is the experience of being readmitted to hospital for people 65 years and over? A review of the literature. Contemporary Nurse: A Journal for the Australian Nursing Profession, 53(6), 698-712. https://doi.org/10.1080/10376178.2018.1439395

Bryant-Lukosius, D., Carter, N., Reid, K., Donald, F., Martin-Misener, R., Kilpatrick, K., Harbman, P., Kaasalainen, S., Marshall, D., Charbonneau-Smith, R., \& DiCenso, A. (2015). The clinical effectiveness and cost-effectiveness of clinical nurse specialist-led hospital to home transitional care: A systematic review. Journal of Evaluation in Clinical Practice, 21(5), 763-781. https://doi.org/10. 1111/jep. 12401

Cao, X. Y., Tian, L., Chen, L., \& Jiang, X. L. (2017). Effects of a hospital-community partnership transitional program in patients with coronary heart disease in Chengdu, China: A randomized controlled trial. Japan Journal of Nursing Science, 14(4), 320331. https://doi.org/10.1111/jjns. 12160

Coleman, E. A., \& Boult, C. (2003). Improving the quality of transitional care for persons with complex care needs. Journal of the American Geriatrics Society, 51(4), 556-557. https://doi.org/10.10 46/j.1532-5415.2003.51186.x

Coleman, E. A., Ground, K. L., \& Maul, A. (2015). The Family Caregiver Activation in Transitions (FCAT) tool: A new measure of family caregiver self-efficacy. The Joint Commission Journal on Quality and Patient Safety, 41(11), 502-507. https://doi.org/10. 1016/s1553-7250(15)41066-9

Coleman, E. A., Mahoney, E., \& Parry, C. (2005). Assessing the quality of preparation for posthospital care from the patient's perspective: The care transitions measure. Medical Care, 43(3), 246-255. https://doi.org/10.1097/00005650-200503000-00007
Coleman, E. A., Parry, C., Chalmers, S., \& Min, S. J. (2006). The care transitions intervention: results of a randomized controlled trial. Archives of Internal Medicine, 166(17), 1822-1828. https://doi.or g/10.1001/archinte.166.17.1822

Dunbar, S. B., Clark, P. C., Quinn, C., Gary, R. A., \& Kaslow, N. J. (2008). Family influences on heart failure self-care and outcomes. Journal of Cardiovascular Nursing, 23(3), 258-265. https://doi.or g/10.1097/01.JCN.0000305093.20012.b8

Feltner, C., Jones, C. D., Cené, C. W., Zheng, Z.-J., Sueta, C. A., Coker-Schwimmer, E. J. L., Arvanitis, M., Lohr, K. N., Middleton, J. C., \& Jonas, D. E. (2014). Transitional care interventions to prevent readmissions for persons with heart failure: A systematic review and meta-analysis. Annals of Internal Medicine, 160 (11), 774-784. https://doi.org/10.7326/M14-0083

Fergenbaum, J., Bermingham, S., Krahn, M., Alter, D., \& Demers, C. (2015). Care in the home for the management of chronic heart failure: Systematic review and cost-effectiveness analysis. Journal of Cardiovascular Nursing, 30(4 Suppl 1), S44-S51. https://doi.or g/10.1097/JCN.0000000000000235

Graumlich, J. F., Novotny, N. L., \& Aldag, J. C. (2008). Brief scale measuring patient preparedness for hospital discharge to home: Psychometric properties. Journal of Hospital Medicine, 3(6), 446454. https://doi.org/10.1002/jhm.316

Hong, Q. N., Fàbregues, S., Bartlett, G., Boardman, F., Cargo, M., Dagenais, P., ... \& Pluye, P. (2018). The Mixed Methods Appraisal Tool (MMAT) version 2018 for information professionals and researchers. Education for Information, 34(4), 285-291. http s://doi.org/10.3233/EFI-180221

Hong, Q. N., Pluye, P., Fàbregues, S., Bartlett, G., Boardman, F., Cargo, M., Dagenais, P., Gagnon, M.-P., Griffiths, F., Nicolau, B., O'Cathain, A., Rousseau, M.-C., \& Vedel, I. (2019). Improving the content validity of the mixed methods appraisal tool: A modified e-Delphi study. Journal of Clinical Epidemiology, 111, 4959.e41. https://doi.org/10.1016/j.jclinepi.2019.03.008

Ishibashi, N., Azuma, M., Fujinaga, S., \& Nishimura, H. (2018). Korei mansei shinfuzen kanja no serufumonitaringu o unagasu enkaku kango kainyu moderu no jissen to yuyo-sei no kensho. [Implementation and efficacy assessment of a telenursing intervention model for promoting self-monitoring of elderly patients with chronic heart failure]. Journal of Japan Academy of Nursing Science, 38, 219-228. https://doi.org/10.5630/jans.38.219

Ishihara, S., Kawakami, R., Nogi, M., Hirai, K., Hashimoto, Y., Nakada, Y., Nakagawa, H., Ueda, T., Nishida, T., Onoue, K., Soeda, T., Okayama, S., Watanabe, M., \& Saito, Y. (2020). Incidence and clinical significance of 30-day and 90-day rehospitalization for heart failure among patients with acute decompensated heart failure in Japan-From the NARA-HF study. Circulation Journal: Official journal of the Japanese Circulation Society, 84 (2), 194-202. https://doi.org/10.1253/circj.CJ-19-0620

Ito, A., \& Tanaka, A. (2018). Kangoshi ni yoru seikatsu shido kainyu wa shinfuzen kanja no sai nyuin risuku o keigen suru. [Health guidance by nurse reduces the risk of rehospitalization in patients with hear failure]. The Journal of Japanese Association of Cardiovascular Nursing, 13(2), 29-36.

Kanaoka, K., Okayama, S., Nakai, M., Sumita, Y., Nishimura, K., Kawakami, R., Okura, H., Miyamoto, Y., Yasuda, S., Tsutsui, H., Komuro, I., Ogawa, H., \& Saito, Y. (2019). Hospitalization costs for patients with acute congestive heart failure in Japan. Circulation Journal: Official journal of the Japanese Circulation Society, 
83(5), 1025-1031. https://doi.org/10.1253/circj.CJ-18-1212

Kato, N. P., Kinugawa, K., Sano, M., Kogure, A., Sakuragi, F., Kobukata, K., Ohtsu, H., Wakita, S., Jaarsma, T., \& Kazuma, K. (2016). How effective is an in-hospital heart failure self-care program in a Japanese setting? Lessons from a randomized controlled pilot study. Patient Preference And Adherence, 10, 171181. https://doi.org/10.2147/PPA.S100203

Kelkar, A. A., Spertus, J., Pang, P., Pierson, R. F., Cody, R. J., Pina, I. L., Hernandez, A., \& Butler, J. (2016). Utility of patient-reported outcome instruments in heart failure. JACC: Heart Failure, 4(3), 165-175. https://doi.org/10.1016/j.jchf.2015.10.015

Kinugasa, Y., Kato, M., Sugihara, S., Yanagihara, K., Yamada, K., Hirai, M., \& Yamamoto, K. (2014). Multidisciplinary intensive education in the hospital improves outcomes for hospitalized heart failure patients in a Japanese rural setting. BMC Health Services Research, 14(1), 351. https://doi.org/10.1186/1472-696314-351

Kotooka, N., Kitakaze, M., Nagashima, K., Asaka, M., Kinugasa, Y., Nochioka, K., Mizuno, A., Nagatomo, D., Mine, D., Yamada, Y., Kuratomi, A., Okada, N., Fujimatsu, D., Kuwahata, S., Toyoda, S., Hirotani, S.-I., Komori, T., Eguchi, K., Kario, K., ... Node, K. (2018). The first multicenter, randomized, controlled trial of home telemonitoring for Japanese patients with heart failure: Home telemonitoring study for patients with heart failure (HOMES-HF). Heart and Vessels, 33(8), 866-876. https://doi.org/10.1007/s0038 0-018-1133-5

Mai Ba, H., Son, Y.-J., Lee, K., \& Kim, B.-H. (2020). Transitional care interventions for patients with heart failure: An integrative review. International Journal of Environmental Research and Public Health, 17(8), 2925. https://doi.org/10.3390/ijerph1708292 5

Mitchell, S. E., Laurens, V., Weigel, G. M., Hirschman, K. B., Scott, A. M., Nguyen, H. Q., Howard, J. M., Laird, L., Levine, C., Davis, T. C., Gass, B., Shaid, E., Li, J., Williams, M. V., \& Jack, B. W. (2018). Care transitions from patient and caregiver perspectives. Annals of Family Medicine, 16(3), 225-231. https://doi.org/1 $0.1370 / \mathrm{afm} .2222$

Mizukawa, M., Moriyama, M., Yamamoto, H., Rahman, M. M., Naka, M., Kitagawa, T., Kobayashi, S., Oda, N., Yasunobu, Y., Tomiyama, M., Morishima, N., Matsuda, K., \& Kihara, Y. (2019). Nurse-led collaborative management using telemonitoring improves quality of life and prevention of rehospitalization in patients with heart failure. International Heart Journal, 60(6), 12931302. https://doi.org/10.1536/ihj.19-313

Murtaugh, C. M., Deb, P., Zhu, C., Peng, T. R., Barrón, Y., Shah, S., Moore, S. M., Bowles, K. H., Kalman, J., Feldman, P. H., \& Siu, A. L. (2017). Reducing readmissions among heart failure patients discharged to home health care: Effectiveness of early and intensive nursing services and early physician follow-up. Health Services Research, 52(4), 1445-1472. https://doi.org/10.1111/1475-677 3.12537

Naylor, M. D., Hirschman, K. B., Toles, M. P., Jarrín, O. F., Shaid, E., \& Pauly, M. V. (2018). Adaptations of the evidence-based transitional care model in the US. Social Science \& Medicine, 213, 2836. https://doi.org/10.1016/j.socscimed.2018.07.023

Nordfonn, O. K., Morken, I. M., Bru, L. E., \& Husebø, A. M. L. (2019). Patients' experience with heart failure treatment and selfcare-A qualitative study exploring the burden of treatment. Journal of Clinical Nursing, 28(9-10), 1782-1793. https://doi.org/ 10.1111/jocn. 14799

Okura, Y., Ramadan, M. M., Ohno, Y., Mitsuma, W., Tanaka, K., Ito, M., Suzuki, K., Tanabe, N., Kodama, M., \& Aizawa, Y. (2008). Impending epidemic: future projection of heart failure in Japan to the year 2055. Circulation Journal, 72(3), 489-491. https://doi.or g/10.1253/circj.72.489

Otsu, H., \& Moriyama, M. (2011). Effectiveness of an educational self-management program for outpatients with chronic heart failure. Japan Journal of Nursing Science, 8(2), 140-152. https://doi. org/10.1111/j.1742-7924.2010.00166.x

Otsu, H., \& Moriyama, M. (2012). Follow-up study for a disease management program for chronic heart failure 24 months after program commencement. Japan Journal of Nursing Science, 9(2), 136-148. https://doi.org/10.1111/j.1742-7924.2011.00194.x

Rice, H., Say, R., \& Betihavas, V. (2018). The effect of nurse-led education on hospitalisation, readmission, quality of life and cost in adults with heart failure. A systematic review. Patient Education and Counseling, 101(3), 363-374. https://doi.org/10.1016/j.pec.20 17.10 .002

Rosa, G. M., Scagliola, R., Ghione, P., Valbusa, A., Brunelli, C., Carbone, F., Montecucco, F., \& Monacelli, F. (2019). Predictors of cardiovascular outcome and rehospitalization in elderly patients with heart failure. European Journal of Clinical Investigation, 49 (2), e13044. https://doi.org/10.1111/eci.13044

Savarese, G., \& Lund, L. H. (2017). Global Public Health Burden of Heart Failure. Cardiac failure review, 3(1), 7-11. https://doi.org/1 0.15420/cfr.2016:25:2

Son, Y. J., \& You, M. A. (2015). Transitional care for older adults with chronic illnesses as a vulnerable population: Theoretical framework and future directions in nursing. Journal of Korean Academy Of Nursing, 45(6), 919-927. https://doi.org/10.4040/jkan.201 5.45.6.919

Takabayashi, K., Ikuta, A., Okazaki, Y., Ogami, M., Iwatsu, K., Matsumura, K., Ikeda, T., Ichinohe, T., Morikami, Y., Yamamoto, T., Fujita, R., Takenaka, K., Takenaka, H., Haruna, Y., Muranaka, H., Ozaki, M., Kitamura, T., Kitaguchi, S., \& Nohara, R. (2016). Clinical characteristics and social frailty of super-elderly patients with heart failure-The Kitakawachi clinical background and outcome of heart failure registry. Circulation Journal: Official journal of the Japanese Circulation Society, 81(1), 69-76. https://doi.o rg/10.1253/circj.CJ-16-0914

Tsuchihashi-Makaya, M., Matsuo, H., Kakinoki, S., Takechi, S., Kinugawa, S., Tsutsui, H., \& J-HOMECARE Investigators (2013). Home-based disease management program to improve psychological status in patients with heart failure in Japan. Circulation Journal: Official journal of the Japanese Circulation Society, 77 (4), 926-933. https://doi.org/10.1253/circj.cj-13-0115

Tomura, H., Yamamoto-Mitani, N., Nagata, S., Murashima, S., \& Suzuki, S. (2011). Creating an agreed discharge: Discharge planning for clients with high care needs. Journal of Clinical Nursing, 20(3-4), 444-453. https://doi.org/10.1111/j.1365-2702.2010.03556. $\mathrm{x}$

Tsutsui, H., Tsuchihashi-Makaya, M., Kinugawa, S., Goto, D., \& Takeshita, A. (2006). Clinical characteristics and outcome of hospitalized patients with heart failure in Japan. Circulation Journal: Official journal of the Japanese Circulation Society, 70(12), 1617-1623. https://doi.org/10.1253/circj.70.1617

van Seben, R., Reichardt, L. A., Essink, D. R., van Munster, B. C., Bosch, J. A., \& Buurman, B. M. (2019). "I Feel Worn Out, as if I 
Neglected Myself': Older patients' perspectives on post-hospital symptoms after acute hospitalization. The Gerontologist, 59(2), 315-326. https://doi.org/10.1093/geront/gnx192

Van Spall, H. G. C., Lee, S. F., Xie, F., Ko, D. T., Thabane, L., Ibrahim, Q., Mitoff, P. R., Heffernan, M., Maingi, M., Tjandrawidjaja, M. C., Zia, M. I., Panju, M., Perez, R., Simek, K. D., Porepa, L., Graham, I. D., Haynes, R. B., Haughton, D., \& Connolly, S. J. (2018). Knowledge to action: Rationale and design of the Patient-Centered Care Transitions in Heart Failure (PACT-HF) stepped wedge cluster randomized trial. American Heart Journal, 199, 75-82. https://doi.org/10.1016/j.ahj.2017.12.013

Van Spall, H. G. C., Lee, S. F., Xie, F., Oz, U. E., Perez, R., Mitoff, P. R., Maingi, M., Tjandrawidjaja, M. C., Heffernan, M., Zia, M. I., Porepa, L., Panju, M., Thabane, L., Graham, I. D., Haynes, R. B., Haughton, D., Simek, K. D., Ko, D. T., \& Connolly, S. J. (2019). Effect of patient-centered transitional care services on clinical outcomes in patients hospitalized for heart failure: The PACT-HF randomized clinical trial. JAMA, 321(8), 753-761. http s://doi.org/10.1001/jama.2019.0710

Van Spall, H. G. C., Rahman, T., Mytton, O., Ramasundarahettige, C., Ibrahim, Q., Kabali, C., Coppens, M., Brian Haynes, R., \& Connolly, S. (2017). Comparative effectiveness of transitional care services in patients discharged from the hospital with heart fail- ure: A systematic review and network meta-analysis. European Journal of Heart Failure, 19(11), 1427-1443. https://doi.org/10.10 02/ejhf.765

Weiss, M. E., \& Piacentine, L. B. (2006). Psychometric properties of the readiness for hospital discharge scale. Journal of Nursing Measurement, 14(3), 163-180. https://doi.org/10.1891/jnm-v14i3a 002

Werner, N. E., Tong, M., Borkenhagen, A., \& Holden, R. J. (2019). Performance-shaping factors affecting older adults' hospital-tohome transition success: A systems approach. The Gerontologist, 59(2), 303-314. https://doi.org/10.1093/geront/gnx199

Whittemore, R., \& Knafl, K. (2005). The integrative review: Updated methodology. Journal of Advanced Nursing, 52(5), 546-553. http s://doi.org/10.1111/j.1365-2648.2005.03621.x

Yamazaki, Y., Nanamori, A., \& Chikamori, S. (2016). Shinfuzen kanja ni taisuru taiin shien shisutemu no koka. [Effect of a discharge support system for patients with heart failure]. The Journal of Japanese Association of Cardiovascular Nursing, 12(1), 26-32.

Yoshimura, M., Sato, M., \& Sumi, N. (2018). Validity and reliability of the Japanese version of the Care Transitions Measure. The International Journal of Health Planning and Management, 33(2), 380-390. https://doi.org/10.1002/hpm.2472 